See discussions, stats, and author profiles for this publication at: https://www.researchgate.net/publication/350490160

\title{
Blended system thinking approach to strengthen the education and training in university-industry research collaboration
}

Article in Technology Analysis and Strategic Management · March 2021

DOl: 10.1080/09537325.2021.1905790

\section{CITATIONS}

5 authors, including:

Adnan Shahid Khan

University Malaysia Sarawak

1 PUBLICATION 0 CITATIONS

SEE PROFILE

slan Amat Senin

Universiti Teknologi Malaysia

74 PUBLICATIONS 549 CITATIONS

SEE PROFILE
101

Narayanan Kulathuramaiyer

University Malaysia Sarawak

103 PUBLICATIONS 523 CITATIONS

SEE PROFILE

Some of the authors of this publication are also working on these related projects:

Government Policy contribution in the relationship between the critical success factors and business incubator performance View project

A Computational Approach for Predicting Software Quality in Use From Software Reviews View project 


\section{Technology Analysis \& Strategic Management}

\section{Blended system thinking approach to strengthen the education and training in university-industry research collaboration}

Abeda Muhammad Iqbal, Adnan Shahid Khan, Johari Abdullah, Narayanan Kulathuramaiyer \& Aslan Amat Senin

To cite this article: Abeda Muhammad Iqbal, Adnan Shahid Khan, Johari Abdullah, Narayanan Kulathuramaiyer \& Aslan Amat Senin (2021): Blended system thinking approach to strengthen the education and training in university-industry research collaboration, Technology Analysis \& Strategic Management, DOI: 10.1080/09537325.2021.1905790

To link to this article: https://doi.org/10.1080/09537325.2021.1905790

\section{1.}

Submit your article to this journal

View related articles

View Crossmark data $\nearrow$ 


\title{
Blended system thinking approach to strengthen the education and training in university-industry research collaboration
}

\author{
Abeda Muhammad lqbal ${ }^{\mathrm{a}}$, Adnan Shahid Khan ${ }^{\mathrm{b}}$, Johari Abdullah ${ }^{\mathrm{b}}$, \\ Narayanan Kulathuramaiyer ${ }^{\mathrm{a}}$ and Aslan Amat Senin ${ }^{c}$ \\ ${ }^{a}$ Institute of Social Informatics \& Technological Innovation, Universiti Malaysia Sarawak, Kota Samarahan, Malaysia; \\ ${ }^{\mathrm{b}}$ Faculty of Computer Science and Information Technology, Universiti Malaysia Sarawak, Kota Samarahan, Malaysia; \\ 'Faculty of Management, Universiti Teknologi Malaysia, Johor Bahru, Malaysia
}

\begin{abstract}
University-industry research collaboration (UIRC) is a major source for research and innovations and economic growth. Despite the extensive evidence on the importance of such collaboration in developed and developing countries, the literature related to strengthen such collaboration along with its innovation performance is still scarce. Scholars believed that the impact of education and training on researchers haa a vigorous influence on research and innovations. Moreover, to enhance the competencies of education and training on researchers, it is mandatory to refurbish education and skills system in conjunction with technological infrastructure system along with their reinforcing factors i.e. knowledge sharing and research and development cooperation, respectively. In this paper, we evaluate the influence of education and skills and technological infrastructure system along with their corresponding reinforcing factors in the blended system thinking method to strengthen education and training. Evidence from UIRC in Malaysia provides empirical corroboration that the role of education and skills system and technological infrastructure system along with their reinforcing factors have a positive influence on education and training. Thus, the findings of this research suggest that intensifying the quality of education and skills system and technological infrastructure system with the reinforcing effect can enhance the effectiveness of education and training.
\end{abstract}

\section{ARTICLE HISTORY}

Received 8 September 2020

Revised 24 February 2021

Accepted 11 March 2021

\section{KEYWORDS}

University-industry research collaboration; education and skills system; system thinking; national innovation system

\section{Introduction}

University-industry research collaboration (UIRC) is one of the key components that deliver potential pathways to accelerate the economies of the nation (lqbal 2018; Jones and Coates 2020; Lin and Yang 2020; Messeni Petruzzelli and Murgia 2020; Ting, Yahya, and Tan 2020). Regardless of extensive significance of UIRC, the existing literature suggested that the rate of technological innovation from UIRC is not satisfactory in several developing countries (Khayyat and Lee 2015; Bohin 2018; Parmentola, Ferretti, and Panetti 2020; Tseng, Huang, and Chen 2020). Several studies were conducted to explore the factors that can enhance such rate of technological innovation by minimalising the barriers of UIRC. Nevertheless, mostly focused on university-industry orientation-related factors, for instance, conducting workshops and seminars, hiring educated, trained and skilled personnel (Brazile et al. 2018; Dooley and Gubbins 2019; Chen, Lu, and Wang 2020) which usually act as a symptomatic way out of the problem (Iqbal 2018). 
Furthermore, universities and industries are the primary components of national innovation system (NIS) that directly performs technological innovation, while the factors of NIS are the secondary components that influence the interactions within the main component (UIRC) (Iqbal 2018; Chen et al. 2019). In this regard, Messeni Petruzzelli and Murgia (2020) emphasised that if the aim is to foster effective innovation, it is advisable to investigate the influence of the factors of NIS on the efficiency of UIRC. However, comprehensive literature about the factors related to the NIS and their influences on UIRC is still scarce.

Secondly, the main limitation of the current literature is the use of analytical thinking approach, which analyses the efficiency of specific parts or elements within the system from a linear perspective, thus has limited predictability of the outcomes (Fuentes and Dutrénit 2012; Freitas, Geuna, and Rossi 2013; Iqbal, Khan, and Senin 2015; Kafouros et al. 2015). Moreover, as universities and industries are the elements of the NIS, they maintain their existence through the mutual interaction of their secondary parts that lead to the construction of circular causality and demand a systemic approach for its evaluation (Melamed-Varela et al. 2019; Razorenov and Vodenko 2020; Wilson et al. 2020). Thus, only sequential consideration allows recognising fundamental weaknesses which consequently provide a sequential cause of the problem and the methods to cover it, which is impossible to achieve when using the analytical or linear model (Befus et al. 2018; Allender et al. 2019).

This study aims to investigate the influence of key factors of NIS on its secondary factor of URIC to strengthen the technological innovation in UIRC. In addition, this study proposes the use of system thinking approach instead of analytical thinking. System thinking approach not only focuses on the linear parts of the system but also focuses on their patterns and events and describes how they work together (circular causality). Furthermore, system thinking not only provides the sequential solution of the problem but also comes up with the reinforcing factors that can reinforce the system (Sarriot et al. 2015). Thus, by utilising the system thinking approach, education and training (ET) is identified as the main constraint between UIRC. It consequently provides the solution to diminish the constraints by indicating the factors, education and skills system (ESS) and technological infrastructure system (TIS) as the critical factors of NIS. Furthermore, knowledge sharing (KS) and R\&D cooperation (RDC) are identified as the reinforcing factors to maximise the technological innovation of UIRC. Extensive and exhaustive discussion is elaborated in Section 2.2.

This research includes five main contributions. First, it contributes to the growing debate on UIRC and presents a theory of system thinking as a practical solution to enhance their rate of technological innovation capabilities. Second, the theory of system thinking previously has not been used in the studies of UIRC. This research proves the efficacy of the theory of system thinking in the same context. Thirdly, this research extends the literature of UIRC with the influence of the critical factors of NIS by illustrating the applicability of the theory of system thinking. Fourth, this research provides the reinforcing factors that can reinforce the innovative capability of UIRC. Finally, this research has practical implications for policymakers who can consider the theory of system thinking and the ESS and TIS as the significant factors to receive the valuable outcomes from the country's universities and industries in the shape of the new research and innovations.

The paper is structured as follows: Section 2 briefly discusses literature review and hypothesis development, detailed methodology is illustrated in Section 3. Section 4 provides results and analysis of the study followed by conclusion and recommendations in Section 5.

\section{Literature review and hypothesis development}

\subsection{System thinking approach in UIRC}

The theory of system thinking originally is used in the biological sciences; basically, this theory was developed in the Second World War to analyse and to deal with the complex problems for policy making or military planning. System thinking seeks to answer the question of how parts are interconnected with each other. This theory critically encourages a consideration of interrelationships 
(Senge 2006; Wilson et al. 2020). White (1995) compared system thinking with analytical thinking and explained that analytical thinking is the concept in which analysis of the system is shown with the help of the individual part. Whereas, system thinking is a tool that makes sense how parts work together (Sedlacko, Martinuzzi, and Dobernig 2014; lqbal, Khan, and Senin 2015).

System thinking has a major focus of examining the effect of one factor on another, and it can be considered as a modelling tool to identify factors that need to be improved in order that optimum results are achieved in a specific subject with the minimisation or elimination of possible barriers (Agyepong et al. 2014; Befus et al. 2018). An important feature of the system thinking is the demonstration of circular causality. Therefore, causal relations are developed as a series of cause and effect. The essential idea behind the cause and effect is an information-action-consequences paradigm (Kunc 2008). The action that is based upon the information is attempted creates consequences. These consequences generate further information and actions, which may, in turn, continue the process. System thinking viewed problem situations in terms of the relationships of each part of the system (Wilson et al. 2020).

Additionally, system thinking has two fundamental loops that show the flows in the system (Alzraiee, Moselhi, and Zayed 2012; Sedlacko, Martinuzzi, and Dobernig 2014). These fundamental loops are (a) balancing feedback loop and (b) reinforcing loop. A balancing feedback loop brings corrective action on the system. In other words, balancing loop covers the situation with the problem, if the current level of the situation is down; the balancing loop pushes its up. The key benefit of the balancing loop is its ability to bring the solution to the problem systematically (Sarriot et al. 2015). Arnold and Wade (2015) mentioned that significant effects on the balancing loop can be denoted by the strong $(\rightarrow)$ or weak $(---\rightarrow)$ causal loops. A strong loop shows that a variable has a significant effect on the other, whereas a weak loop demonstrates that a variable does not have a significant effect. While a reinforcing feedback loop reinforces change with even more change. This can lead to rapid growth at an ever-increasing rate. This type of growth pattern is often referred to as exponential growth (Agyepong et al. 2014). In the system thinking model, capital $R$ is used to denote the reinforcing causal loop.

Abundant characteristics system thinking was utilised in several different discipline, such as team building (Behl and Ferreira 2014), quality management (Conti 2006), project management (Fusso, Ducker, and Ito 2013), risk management (Kadarova, Kalafusova, and Darkacova 2014) and for the health organisation analysis (Lane, Munro, and Husemann 2016), but the utilisation of system thinking in the consideration of policy making for research and innovative organisations is still scarce. Subramanian and Wang (2019) indicated that the theory of system thinking is appropriate to study national systems of innovation that shows feedback mechanisms. Similarly, Emery and Trist (1965) used the system-thinking approach to create a framework for evaluating organisational performance. Furthermore, Allender et al. (2019) mentioned that it allows policy makers to better comprehend structural weaknesses and provide the opportunity for developing a framework to make the system successful, which is impossible to achieve when using a linear model. Thus, this research suggests that system thinking is the remarkable theory to enhance the efficiencies of UIRC by investigating the influence of NIS.

\subsection{Hypothesis development}

It is generally accepted that education and training (ET) are the mantras for the continuous development of research and innovations and the economic competitiveness (Lai and Lu 2016; Firsova, Lukashenko, and Azarova 2021). Researchers found that highly educated and trained personnel highly contribute to the development of research and innovations (Higueras-Rodríguez, MedinaGarcía, and Molina-Ruiz 2020; Veis et al. 2021). However, it is observed that when UIRC is formed, ET is one of the major constraints between them (Brimble and Doner 2007; Davenport, Crick, and Hourizi 2020). Specifically, in lower-income countries primitive methods of teaching and training are still followed in universities to educate and train the personnel: following the old syllabus for 
teaching, mindset curriculum, theory-based curriculum, and the behaviour of stickiness on their developed curriculum and the like. In addition, industries do collaborate with universities to recruit fresh graduates. If the curriculum does not fulfil industrial requirement, it consequently leads both parties incapable of collaborating or producing innovative outcome (Gámez-Pérez et al. 2020).

In this regard, education and skill system (ESS) in NIS is the factor that triggers the education and training between university-industry personnel (Hooshyar et al. 2020). Perfect ESS always consists of quality of scientific knowledge-producing organisations, quality of teaching and training organisations and quality of internship organisations that are valuable to enhance the output of R\&D activities of UIRC (Bamfield 2013). Pontarollo, Orellana, and Segovia (2020) and Meek, Teichler, and Kearny (2009) elaborated that the standard of ESS in developing countries remains bleak, they require rapid changing where the research-based teaching and training practices can be developed. Similarly, Healey, Jenkins, and Lea (2014) and Bunatovich, Khidayevich, and Abdurakhmonovich (2020) delineated that ESS must have a research-based curriculum rather than a theory-based one; a theorybased curriculum only produced the graduates with theoretical knowledge, which is insufficient for the development of research and innovations. Furthermore, according to Guimón (2013) and Firsova, Lukashenko, and Azarova (2021) advance methods of teaching, learning, and training in ESS can boost up the research and innovation capabilities between universities and industries. In this regard, this research hypothesised that:

H1a: Education and skill system in NIS has a positive influence on education and training between UIRC.

Similarly, Eid (2012) examines the impact of technological infrastructure system (TIS) on productivity growth in 17 high-income organisations for economic co-operation and development (OECD) countries using country-level data over the period 1981-2006. The results concluded that $R \& D$ performed by highly educated and trained personnel is positively affecting productivity growth in all specifications. Similarly, productivity growth that is crucial to sustain the economies is only possible with the well-developed research and innovative organisations (lqbal et al. 2011, 2013). New or changing practices, programmes, policies, and agendas are transforming TIS worldwide. From the notions and perceptions of 'global competency' a strong TIS is a desirable objective in a changing global scale and context (Lee and Lee 2020). A national TIS encompasses the quality of research institutions, quality of industries, and training management institutions that provide facilities to UIRC to create research and innovations. In this regard, a well-structured TIS in a country is also one of the main instruments to enhance learning capabilities, absorptive capacities, and technological competencies of UIRC (Hamidi et al. 2020). Thus, this research hypothesised that:

H2a: Technological infrastructure system in NIS has a positive influence on education and training between UIRC.

Furthermore, according to the theory of system thinking, the system can generate its desired condition. Considering actual condition and after corrective actions, by taking some reinforcing action, the desired condition can be achieved in a system. Thus, this research proposes some reinforcing factors to reinforce the ET of UIRC, such as knowledge sharing (KS) between ESS enables the research organisation to capitalise on its facilities and resources (Dehghani 2020). Contributors to the literature share the presumption that different sectors of NIS, specifically, ESS in NIS enable that the organisations must be competent enough to provide specific knowledge and resources that are relevant to the enhancement of research and innovations (Wang and Noe 2010; lqbal, Khan, and Senin 2012). Thus, to reach the performance goals, it is important for the organisations to exploit the knowledge resources that already exist in the ESS (Wang and Noe 2010; Messeni Petruzzelli and Murgia 2020). Thus, to maximise the innovative performance of UIRC, KS as a reinforcing factor is induced at the ESS. This reinforcing factor boosts the capabilities of ESS, which consequently positively influences the ET of university-industry personnel. Thus, the research hypothesises that: 
$\mathrm{H} 1 \mathrm{~b}$ : Knowledge sharing as a reinforcing factor of education and skill system has a positive influence on education and training between UIRC.

Similarly, to maximise the innovative performance of UIRC, this research proposes research and development cooperation (RDC) as a reinforcing factor. RDC boosts the overall capabilities of TIS in NIS, which consequently enhances the ET of UIRC (Cantabene and Grassi 2020). RDC is the cooperative behaviour where different sectors engage in various decision makings and by spreading their knowledge, skills and resources enhance the capabilities and performances of organisations (Wu et al. 2020).

$\mathrm{H} 2 \mathrm{~b}$ : Research and development cooperation as a reinforcing factor of technological infrastructure system has a positive influence on education and training of UIRC.

The in-depth system thinking-based influence of ESS on E\&T, TIS on E\&T with their balancing and reinforcing factors and complete theoretical framework can be visualised in Figures 1-3, respectively.

\section{Methodology}

In this study, a survey approach based on the positivism paradigm was utilised, where an openended questionnaire is used for data collection. In this paradigm, data, evidence and rational consideration first shape the knowledge and later hypothesis is tested with the help of statistical method and make claims (Phillips and Burbules 2000; Park, Konge, and Artino 2020). Furthermore, the theory of system thinking and the verified statistical software smart PLS and SPSS were utilised for the elaboration and proof of our hypothesis. As the study contained technological innovations, the data for this study were obtained from all research universities (RU) in Malaysia which are known to be excellent in research and innovation. From RUs, two departments were chosen: departments of electrical and chemical engineering. From the webometric search, it has been analysed that both departments have more research groups and industrial collaboration than other departments. Thus, the two departments and their collaborated industries were selected as respondents. In this study, top-tier academic professors (universities) and top management from collaborated industries were identified as an individual unit analysis to meet the requirements for answering the research questions. The total population of both departments is 500 approximately. Thus, according to the table of Krejcie and Morgan (1970) in 500 populations with $95 \%$ confidence level, the required

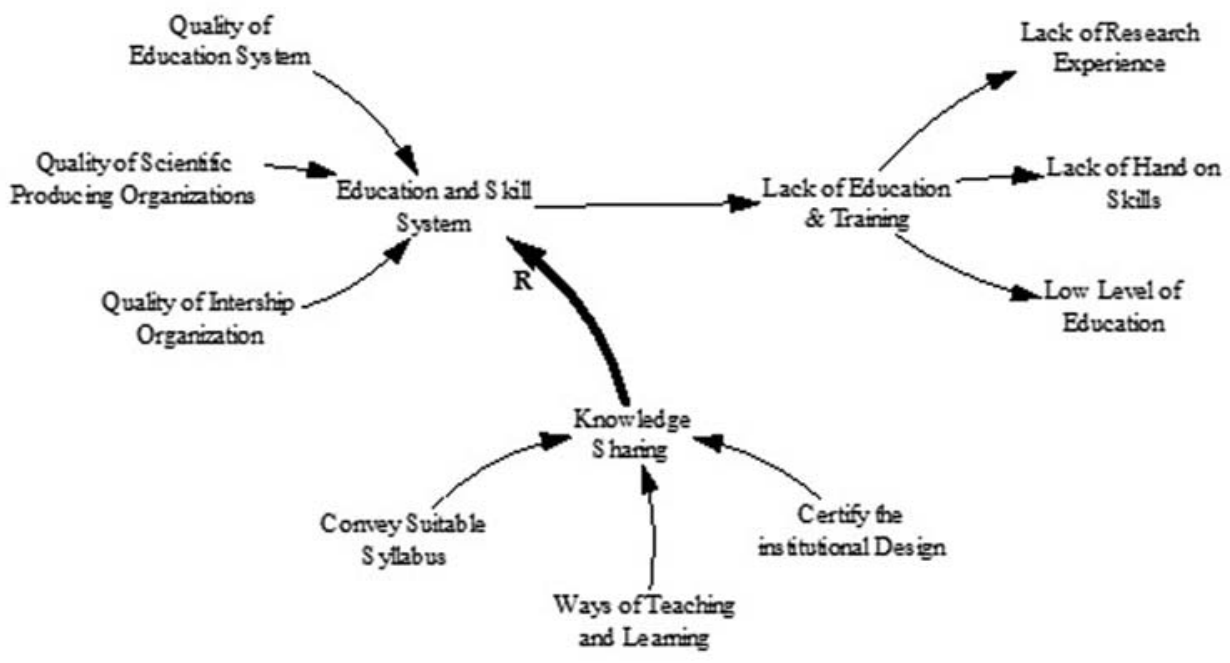

Figure 1. Influence of ESS on E\&T. 


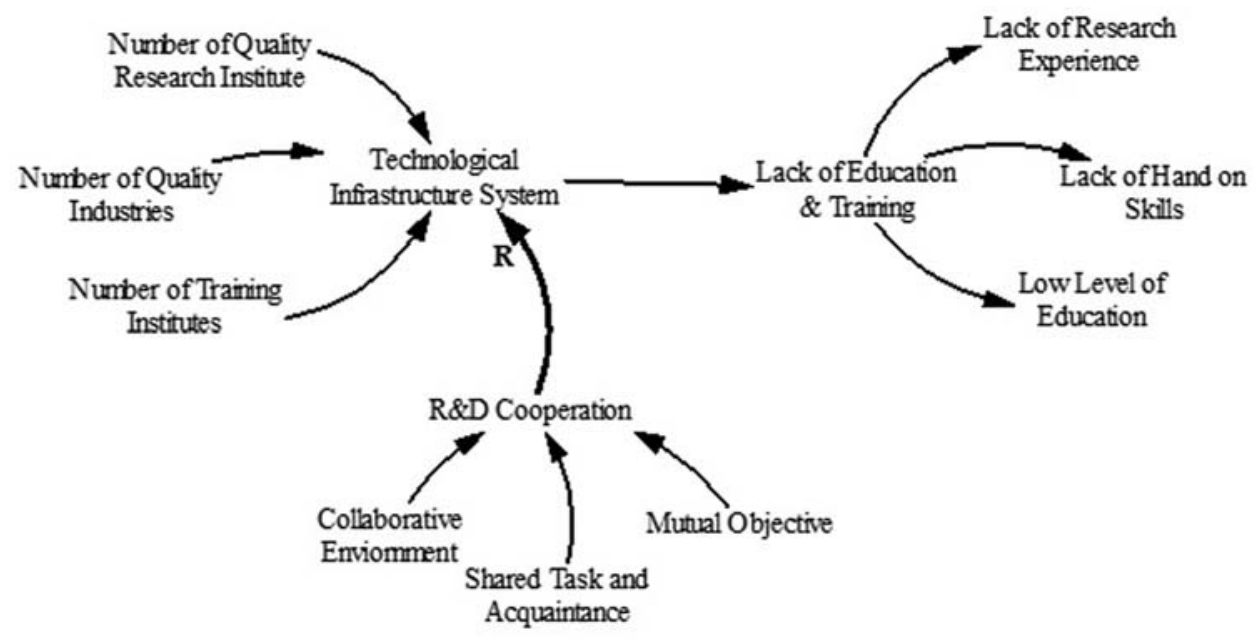

Figure 2. Influence of TIS on E\&T.
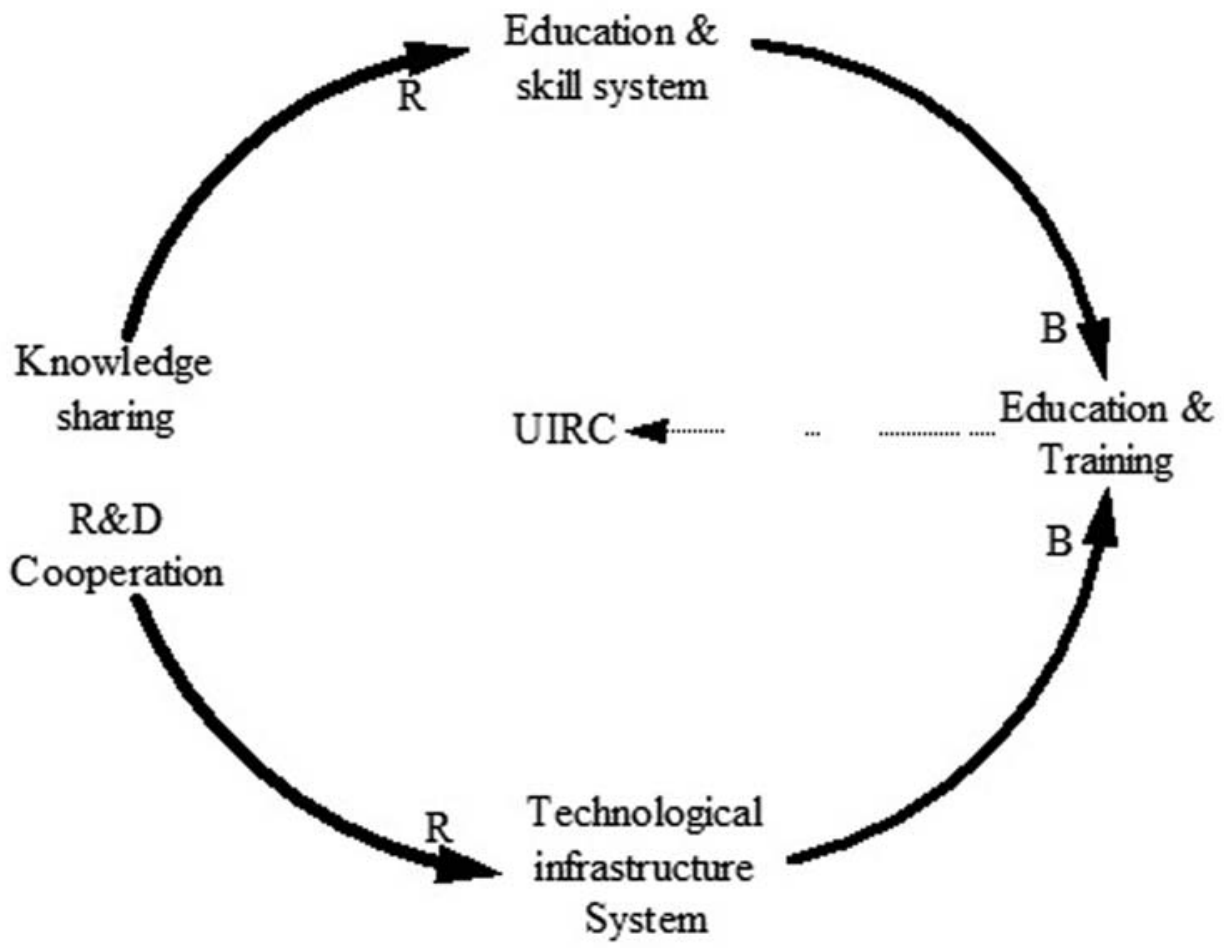

Figure 3. Theoretical framework using system thinking.

respondents are 210. However, in this research, evidence has been collected from 214 respondents to obtain more accurate results. Our research instrument includes ET as a dependent variable, ESS \& TIS, as independant variable while KS \& RDC as reinforcing variables. Valid variables were selected from the previous studies and measured based upon the scope of the current study. Table 1 
Table 1. Variables, constructs and items of research instruments.

\begin{tabular}{|c|c|c|c|}
\hline Variables & Constructs & $N$ & Items \\
\hline \multirow[t]{3}{*}{ DV } & ET & 1 & Methods of teaching and training \\
\hline & & 2 & Curriculum of teaching and training \\
\hline & & 3 & Theory-based teaching perceptions \\
\hline \multirow[t]{7}{*}{ IDV } & ESS & 1 & Quality of knowledge-producing organisations \\
\hline & & 2 & Research-based curriculum for teaching and training \\
\hline & & 3 & Research-based methodologies for teaching and training \\
\hline & TIS & 1 & Quality of research centres \\
\hline & & 2 & Research-based industries \\
\hline & & 3 & Quality of training institutes \\
\hline & & 4 & Quality of knowledge access to providing institutions \\
\hline \multirow[t]{4}{*}{ RF } & $\mathrm{RDC}$ & 1 & Collaborative capabilities to contribute to innovation \\
\hline & & 2 & Collaborative provision of knowledge, skills, and resources \\
\hline & KS & 1 & Relevant sharing of knowledge and resources among research groups \\
\hline & & 2 & Transfer and implement new ideas and experiences among research groups \\
\hline
\end{tabular}

shows dependent variable (DV), independent variable (IDV) and the reinforcing factors (RF), with their corresponding constructs and items.

\section{Results, analysis and discussion}

For the data analysis, SPSS and Partial least square analysis (PLS) were utilised. Here is to mention that Section 2 clearly shows all variables of this study are formative. In this regard, for the evaluation of the formative path model, assessment of the measurement and structure model must be carried out sequentially (Liu 2017).

\subsection{Assessment of the measurement model}

This model describes how the latent constructs are measured in terms of their measurement properties. In this regard, the measurement model is assessed by measuring the validity of the constructs and their indicators.

\subsubsection{Assessment of construct validity}

At the construct level, it is suggested that there should not be redundancy between the constructs. For this purpose, multicollinearity is deduced for each of the constructs. Multicollinearity occurs when there is a high correlation between two or more variables in the model. Estimates of a regression coefficient become unreliable if there is multicollinearity between the variables. The present study has five variables; thus, sufficient efforts were made to operationalise those variables properly.

For construct validity, the variance of inflation factors (VIF) was tested to evaluate the possibility of multicollinearity issues. Based on Hair et al. (2014) for formative construct VIF must not be greater than 5 and tolerance should be higher than 0.20 . Table 2 shows the VIF test by running the stepwise regression analysis for each construct. The result indicated that all the VIFs are less than 5 and all the tolerance values are above 0.20 ; consequently, no sign of multicollinearity was found.

\subsubsection{Assessment of indicator validity}

At the indicator level, the question arises as to whether each indicator delivers a contribution to the construct by carrying the intended meaning. It is suggested that there should be strong relevancy between the indicator and the construct. To check the relevancy of the indicators with their construct, the weight of each indicator is assessed (Henseler and Chin 2009; Tenenhaus and Esposito Vinzi 2005). Furthermore, PLS estimates the indicator weights $(p<1 / \sqrt{ } n)$ that measure the contribution of each indicator to the constructs. Here it is mentioned that in this research minimum 2 
Table 2. Assessment of constructs validity.

\begin{tabular}{|c|c|c|c|}
\hline \multirow[b]{2}{*}{ Constructs } & \multirow[b]{2}{*}{ Indicators } & \multicolumn{2}{|c|}{ Collinearity statistics } \\
\hline & & Tolerance & VIF \\
\hline \multirow[t]{3}{*}{ ET } & ET_1 & 0.999 & 1.001 \\
\hline & ET_2 & 0.886 & 1.128 \\
\hline & ET_3 & 0.886 & 1.129 \\
\hline \multirow[t]{4}{*}{ TIS } & TI_1 & 0.912 & 1.097 \\
\hline & TI_2 & 0.896 & 1.116 \\
\hline & TI_3 & 0.856 & 1.168 \\
\hline & TI_4 & 0.910 & 1.099 \\
\hline \multirow[t]{3}{*}{ ESS } & ES_1 & 0.766 & 1.306 \\
\hline & ES_2 & 0.838 & 1.193 \\
\hline & ES_3 & 0.727 & 1.375 \\
\hline \multirow[t]{2}{*}{$\mathrm{RDC}$} & $\mathrm{RC} \_1$ & 0.715 & 1.399 \\
\hline & RC_2 & 0.715 & 1.399 \\
\hline \multirow[t]{2}{*}{ KS } & KS_1 & 0.700 & 1.429 \\
\hline & KS_2 & 0.700 & 1.429 \\
\hline
\end{tabular}

and maximum 4 indicators have been used for each of the constructs, so $p$-values of 2, 3, and 4 indicators are $0.709,0.578$, and 0.5 , respectively, as shown in Table 3.

Table 3 shows the indicators weight of all the related constructs. The significant item weight indicates that all the indicators explain a significant portion of the variance to their constructs. Two indicators, 'ESS (ES_2)' and 'KS (KS_2)', based on their formulaic value have somehow fluctuated frequency. In this regard, according to Hair et al. (2014), item loadings are also countable when indicators weights are not significant at $(p<1 / \sqrt{n})$. Thus, the item loadings of all the constructs are significant $(p>0.50)$ and show the absolute importance and relevancy with their respective constructs. After having a valid measurement model for this study, the PLS analysis was conducted to assess structural model in the next step phase.

\subsection{Assessment of structural model}

The hypothesised relationships in the structural model, including two main relationships $(\mathrm{H} 1 \mathrm{a}, \mathrm{H} 2 \mathrm{a})$ and two reinforcing effects $(\mathrm{H} 1 \mathrm{~b}, \mathrm{H} 2 \mathrm{~b})$, were examined. The structural model was tested in terms of path coefficients and $R^{2}$ values.

\subsubsection{Results of hypothesis}

The results of the hypothesis have been illustrated with the help of the research model. In this study, the research model has been illustrated in two phases: an initial structural model and the final

Table 3. Assessment of indicators validity.

\begin{tabular}{llcc}
\hline Constructs & Indicators & Indicators weight $(t-V)$ & Indicators loading $(t-V)$ \\
\hline ET & ET_1 & 0.5272 & 0.5399 \\
& ET_2 & 0.5225 & 0.7622 \\
TIS & ET_3 & 0.4997 & 0.7236 \\
& TI_1 & 0.4867 & 0.7598 \\
& TI_2 & 0.2535 & 0.5913 \\
& TI_3 & 0.3261 & 0.6767 \\
ESS & TI_4 & 0.4876 & 0.7424 \\
& ES_1 & 0.0506 & 0.5909 \\
RDC & ES_2 & 0.9275 & 0.9901 \\
& ES_3 & 0.1255 & 0.6933 \\
KS & RC_1 & 0.4503 & 0.8148 \\
& RC_2 & 0.6842 & 0.9253 \\
& KS_1 & 0.0412 & 0.5740 \\
\hline
\end{tabular}


structural model. In more detail, Figure 4 shows the effect of the factors of NIS (ESS) and (TIS) on the constraint (ET) of UIRC. In this regard, path coefficient $(\beta)$ values, indicating the effect of ESS and TIS and the $R^{2}$ values, explain the variances on the ET of UIRC. For instance, $\beta$ values of ESS $(0.575)$ and TIS (0.221) shows significant effects on ET of UIRC. Similarly, $R^{2}$ values of ET $48.5 \%$ show significant variance. Hence Figure 4 proves that ESS and TIS are the critical factors of NIS that can enhance the ET between UIRC.

Furthermore, Figure 5 shows support for the reinforcing role on the factors of NIS and on the constraints of UIRC. By inducing reinforcing factor KS and RDC increased the path coefficients of ESS $(0.575-0.975)$ and TIS $(0.221-0.223)$ to ET. Simultaneously increased the variances $\left(R^{2}\right)$ of ET 0.485 (48.5\%) to $0.498(49.8 \%)$. Figure 5 shows that KS and RDC are the considerable reinforcing factors in enriching the efficiencies of ESS and TIS and consequently enhancing the ET of UIRC. Additionally, $t$-statistics was also examined to investigate the accuracy of each path.

Table 4 shows the results of $t$-statistics values of $\{\mathrm{H} 1$ ( $a$ and $b$ ) and $\mathrm{H} 2$ ( $a$ and $b$ ) $\}$ that are significant at $(p>1.96)$ from their path estimates. Thus, the $t$-statistics of the ESS $(t=15.88)$ and reinforcing factor illustrates that the KS $(t=22.45)$ has a significant effect on the ET. Similarly, the $t$-statistics of the TIS $(t=11.57)$ and reinforcing factor RDC $(t=6.00)$ have a significant effect on ET.

\subsection{Discussion}

Based on the analysis, this research proves that factors of NIS are the critical successful factors to enhance the innovative capabilities of UIRC. It is generally accepted that the existence of appropriate and strong ESS at national level favours the innovative capacity in a country (Maggioni 2002). Perfect ESS not only enhances the individuals' level of education but also supports the output of R\&D activities of UIRC (Hanushek and Ludger 2007). Similarly, TIS of a country works as an institutional focusing device that helps in the development of research and innovations via organising and guiding the collective search for knowledge, learning and transformation of the technologies and provide specific innovation-relevant capabilities to research and development organisations (Justman and Teubal 1995).

Furthermore, this research contributes to the literature by proposing KS and RDC as the reinforcing factors. Although from the analysis of the research, it is coherent that the strong ESS at national level can reduce the constraints of ET, but KS as a reinforcing factor enhances the efficiencies of the national ESS. Similarly, it is quite clear that the strong TIS of NIS always can enhance the ET, but RDC

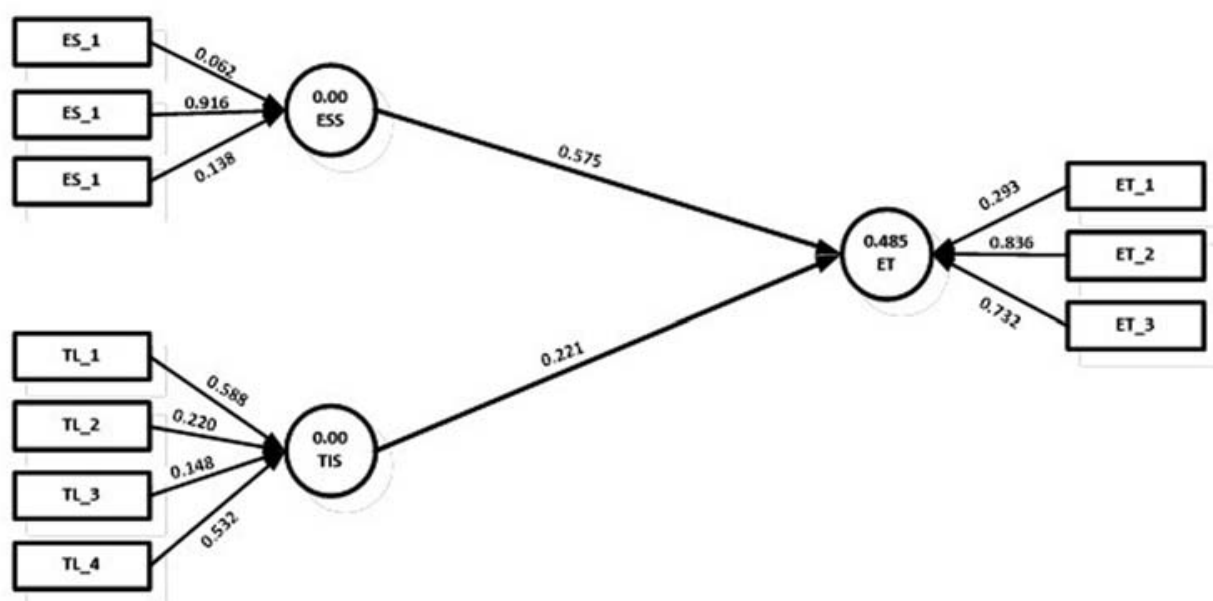

Figure 4. Effect of ESS and TIS on ET. 


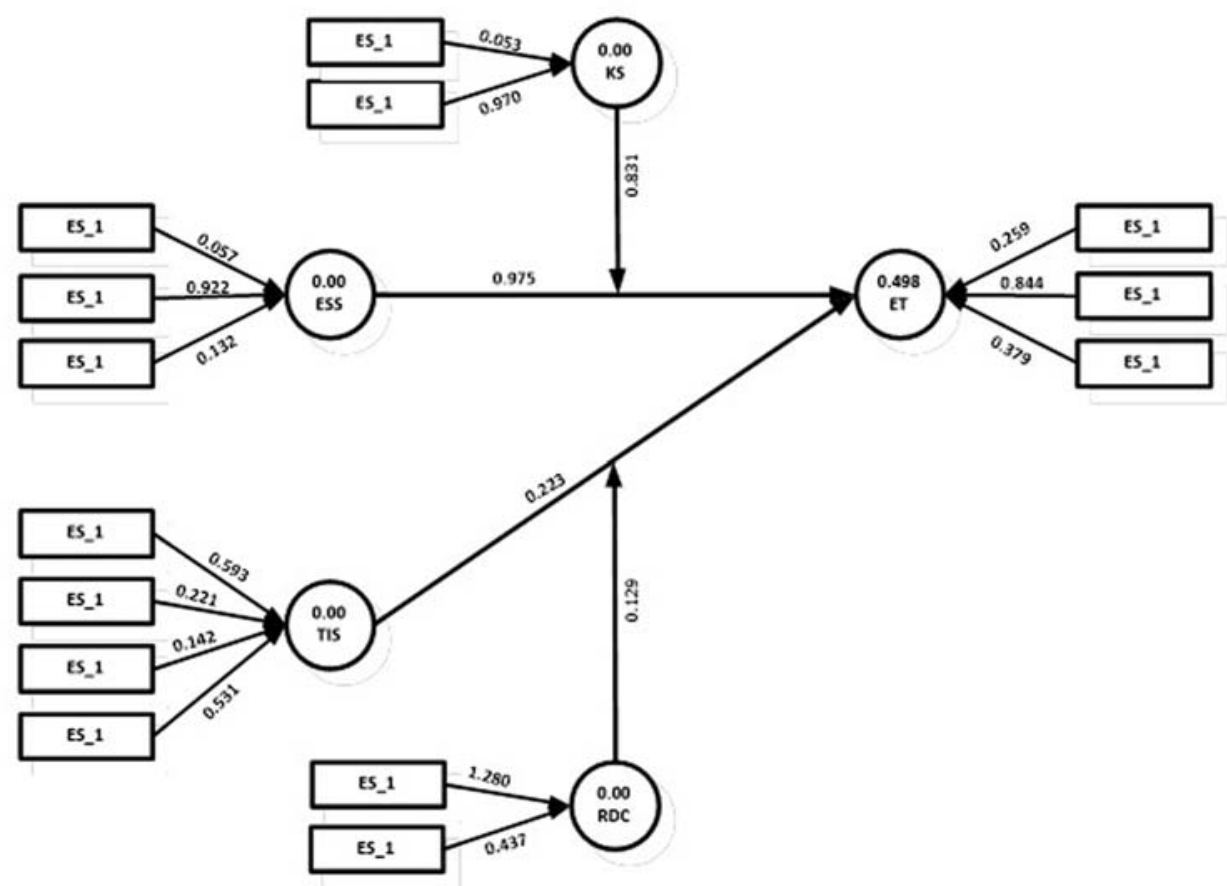

Figure 5. Effect of ESS and TIS on ET.

Table 4. Path coefficient and $t$-statistics.

\begin{tabular}{llccr}
\hline$N$ & Hypothesis & Path coefficient & Standard error & $t$-Statistics \\
\hline H1a & ESS $\rightarrow$ ET & 0.575 & 0.042 & 15.88 \\
H1b & KS $\rightarrow$ ET & 0.831 & 0.037 & 22.45 \\
H2a & TIS $\rightarrow$ ET & 0.221 & 0.042 & 11.57 \\
H2b & RDC $\rightarrow$ ET & 0.129 & 0.028 & 6.00 \\
\hline
\end{tabular}

provides a leading assistance to the TIS to be more efficient for the provision of knowledge and skills to the research organisations.

In addition, this research contributes to the literature by proposing KS and RDC as the reinforcing factors. Although from the analysis of the research, it is coherent that the strong ESS at national level can reduce the constraints of ET, but KS as a reinforcing factor enhances the efficiencies of the national ESS. Similarly, it is quite clear that the strong TIS of NIS always can enhance the ET, but RDC provides a leading assistance to the TIS to be more efficient for the provision of knowledge and skills to the research organisations.

\section{Conclusion and recommendations}

The present study presented a fragmented and long-lasting way of enhancing the innovative capabilities of UIRC. Several studies contribute to the evaluation of UIRC; however, theory-based studies are still scarce. Thus, having a theoretical foundation is the significance of the present study. Our paper attempts to bridge the gap between research and innovation organisations and the policy makers by illustrating the influence of NIS on UIRC. The core competency of the system thinking is that it can be applied in any on-going situation. This research makes a number of contributions. First, it contributes to the growing debate on the constraints and enhancing the research and 
innovative activities in the context of universities and industries (Brimble and Doner 2007; Xu 2013; Li 2011; Azizan 2013; Alexander and Yuriy 2015) and offers a practical solution through system thinking. Theory of system thinking provides a new perspective by considering the factors of NIS as the key success factor to enhance the innovative performance of UIRC.

Second, this research investigated the education and training as the critical constraints of UIRC. An important feature of the system thinking is prompting us to see the cause of the problem. In the macroeconomic environment, a system thinker must observe unseen forces. Thus, system thinking is the theory that helps policy makers to see the patterns of events and to cover it (Richmond 1994; Wilson et al. 2020). Thirdly, this research proves the efficacy of the system thinking by suggesting the factors of NIS; ESS and TIS as the perfect systemic solutions to diminish the constraints of ET. Fourth, this research contributes to the literature by proposing KS and RDC as the reinforcing factors. Lastly from the practical perspective, system thinking can help policy makers by having an extensive and comprehensive knowledge about the influence of (NIS) on (UIRC). In terms of practical implications, this study tried to develop a framework to strengthen the innovative capability of UIRC. In other words, the findings of the current study provide intuition to the policy makers to understand the relationship between the strong system of innovation and the innovative capabilities of UIRC.

This research identifies future research directions that will help in overcoming the limitations of this research. Using Malaysia as a scope of the study, this research proposes comparative works conducted across different other developed and developing countries. Furthermore, replicating the study by comparing other countries could be valuable to identify the major differences in terms of enhancing the innovative capability of UIRC.

\section{Disclosure statement}

No potential conflict of interest was reported by the author(s).

\section{Notes on contributors}

Abeda Muhammad Iqbal (Member of the Malaysian branch of the Royal Asiatic Society) is currently research fellow at Institute of Social Informatics \& Technological Innovation, Universiti Malaysia Sarawak. She received her PhD and Master's degree in Management from Universiti Teknologi Malaysia, Johor Bahru in 2018 and 2012 respectively, and her bachelor in Commerce from University of Karachi, Karachi, Pakistan in 2005. Her research interest includes Technology Management, Innovation and Policy Management, Human Resource Management, Entrepreneurship, UniversityIndustry Research Linkages, Organizational behavior.

Adnan Shahid Khan (Senior Member, IEEE) is currently a Senior Lecturer at Faculty of Computer Science and Information Technology, Universiti Malaysia Sarawak. He has completed his Postdoctoral, PhD and Masters in Networks and Information Security in 2013, 2012, 2008 respectively from Universiti Technology Malaysia, Johor Bahru, Malaysia and BSc (Hons) Computer Sciences in 2005 from University of Punjab, Lahore Pakistan. His research interest includes Security issues in Wireless Communication, Cloud computing, Internet of things, Software Defined Networking, Cryptography, Network and Information Security.

Associate Professor Dr. Johari Abdullah is currently serving at the Faculty of Computer Science \& IT, UNIMAS, Sarawak. He received his PhD (Computing Science) from Newcastle University (UK), his Master of IT from Queensland University of Technology, Brisbane, Australia, and Bachelor of Computer Science (Networking) degree from Universiti Putra Malaysia. His interest in ICT is wide and ranging from Trusted System, Blockchain Technology, Web System Design and development, System Architecture, problem solving using tools such as TRIZ, ICT education for children and youth through Computational Thinking, Scratch and Computer Science Unplugged, and open source system and software.

Professor Dr. Narayanan Kulathuramaiyer has served 24 years of his almost three decades in academia as one of the pioneer staff of Faculty of Computer Science and IT in UNIMAS. He is currently the Director of the Institute of Social Informatics and Technological Innovations (ISITI) and Professor of Computer Science at the Faculty of Computer Science and Information Technology, Universiti Malaysia Sarawak (UNIMAS). He received his PhD in Computer Science from Graz University of Technology, Austria. He has completed supervision of 6 PhD and 14 Masters candidates. He has taught over 20 courses at the Undergraduate and Masters level. In terms of research, he has published around 120 peer-reviewed papers on technology-based learning, data analytics and on making eLearning work in an 
information proliferation era. He has a H-Index of 12, according to Google Scholar. He has pioneered efforts in eLearning from heading the Virtual Campus Programme, Centre of Applied Learning and Multimedia, and initiating UNIMAS' first ever MOOC initiative on IT literacy. He is continuing to impact changes at the national and international levels through his work with remote rural communities across the country, strategy shaping Taskforce on ICT education, promoting MOOC and currently innovating MOOC technology to serve marginalized rural communities in Malaysia, Indonesia and Philippines. He has been instrumental in the Virtual Campus project and online learning efforts in UNIMAS and has produced blueprints for eLearning for UNIMAS in 2001. At the national level he had also been a member of the National IT Council's (NITC) Strategic Taskforce on eLearning from 2000 to 2001. Furthermore he has obtained registered Intellectual Property and the National and International awards for his role in projects such as eBario project and the e-Toro Indigenous Knowledge Management system, Semantic Clustering Toolkit and the e-Co Outcomebased profiling system.

Aslan Amat Senin is Associate Professor of Technology and Innovation Management at AHIBS. He holds Bachelor in Economics (Hitotsubashi University, Monbusho scholar), MSc in Technology Management (UMIST) and PhD in Science Policy Research (Manchester). Before joining UTM in 2000, he has worked for several years as quality and safety management system auditor. His research and teachings are therefore wide-ranging; within or intersections between innovation studies; science, technology and innovation policy research; technology and innovation management; university-industry links; and operation management. Apart from these professional interests, Aslan has also soft spot for history and sociology literature. He is currently editor-in-chief for Jurnal Kemanusiaan (Journal of Humanities) and editor for Sains Humanika (UTM flagship Journal for Social Sciences).

\section{References}

Agyepong, I., G. Aryeetey, J. Nonvignon, B. F. Asenso, H. Dzikunu, E. Antwi, D. Ankrah, et al. 2014. "Advancing the Application of Systems Thinking in Health: Provider Payment and Service Supply Behaviour and Incentives in the Ghana National Health Insurance Scheme - A Systems Approach." Health Research Policy and Systems/BioMed Central 12: 35.

Alexander, C., and H. Yuriy. 2015. "Problems and Perspectives of Performance of Higher Education Institutions in the Development of Russian Innovative System (Regional Aspect)." Procedia - Social and Behavioral Sciences 166: 497-504.

Allender, S., A. D. Brown, K. A. Bolton, P. Fraser, J. Lowe, and P. Hovmand. 2019. "Translating Systems Thinking into Practice for Community Action on Childhood Obesity." Obesity Reviews 20 (2): 179-184.

Alzraiee, H., O. Moselhi, and T. Zayed. 2012. "Dynamic Planning of Earthmoving Projects Using System Dynamics.” 2012 Proceedings of the 29th International Symposium of Automation and Robotics in Construction, ISARC 2012, Eindhoven, Netherlands.

Arnold, R. D., and J. P. Wade. 2015. "A Definition of System Thinking: A Systems Approach.” Procedia 44: 669-678.

Azizan, S. A. 2013. "Strengthening Malaysia's Scientific and Technological Development Through Human Capital Development." Procedia - Social and Behavioral Sciences 91: 648-653.

Bamfield. 2013. "Rebalancing the UK's Education and Skills System. Transforming the Capacity for Innovation and Collaboration.” https://www.thersa.org/globalassets/pdfs/reports/rsa_education_balancing_skills.pdf.

Befus, D. R., L. K. Hassmiller, S. M. Kneipp, J. P. Bettger, R. R. Coeytaux, and J. C. Humphreys. 2018. "A Qualitative, Systems Thinking Approach to Study Self-Management in Women with Migraine." Nursing Research 67 (5): 395-403.

Behl, D. V., and S. Ferreira. 2014. "System Thinking: An Analysis of Key Factors and Relationship." Procedia Computer Science 36: 104-109.

Bohin, P. 2018. "Effectiveness of Innovative Policies to Enhance University-Industry Collaboration in Developing Countries." Towards Technical University-Industry Links in Ghana. British Journal of Education 6 (2): 54-70.

Brazile, T., S. G. Hostetter, C. M. Donough, and D. W. Citters. 2018. "Promoting Innovation: Enhancing Transdisciplinary Opportunities for Medical and Engineering Students." Medical Teacher 40 (12): 1264-1274.

Brimble, P., and R. F. Doner. 2007. "University-Industry Linkages and Economy Development: The Case of Thailand." World Development 35 (6): 1021-1036.

Bunatovich, U. H., D. B. Khidayevich, and O. M. Abdurakhmonovich. 2020. "The Importance of Modern Innovative Teaching Methods in the Higher Education System of Uzbekistan.” Journal of Critical Reviews 7 (7): 1064-1067.

Cantabene, C., and I. Grassi. 2020. "R\&D Cooperation in SMEs: The Direct Effect and the Moderating Role of Human Capital." Applied Economics 52 (28): 3090-3105.

Chen, Y., J. Han, Z. Xuan, and W. Gao. 2019. "Higher Education's Role in Chinese National Innovation System: A Perspective of University-Industry Linkages." In Proceedings of 17th International Conference on Scientometrics and Informetrics, ISSI 2019, Rome, 573-583.

Chen, K., W. Lu, and J. Wang. 2020. "University-Industry Collaboration for BIM Education: Lessons Learned from a Case Study." Industry and Higher Education 34 (6): 401-409.

Conti, T. 2006. "Quality Thinking and System Thinking.” The TQM Magzine 18 (3): 297-308. 
Davenport, J. H., T. Crick, and R. Hourizi. 2020. "The Institute of Coding: A University-Industry Collaboration to Address the UK's Digital Skills Crisis.” Proceedings of IEEE Global Engineering Education Conference, EDUCON (2020), Austria.

Dehghani, M. 2020. "Knowledge-Sharing Mechanisms in a Socio-Technical Collaborative Project in IT-Related Faculties: Preliminary Findings." Proceedings of 27th European Conference on Information Systems - Information Systems for a Sharing Society, ECIS 2019, Sweden.

Dooley, L., and C. Gubbins. 2019. "Inter-Organisational Knowledge Networks: Synthesising Dialectic Tensions of University-Industry Knowledge Discovery." Journal of Knowledge Management 23 (10): 2113-2134.

Eid, A. 2012. "Higher Education R\&D and Productivity Growth: An Empirical Study on High-Income OECD Countries." Education Economics 20 (1): 53-68.

Emery, F. E., and E. L. Trist. 1965. "The Causal Texture of Organizational Environments Human Relations." Human Relations 18 (1): 21-30.

Firsova, I. A., I. V. Lukashenko, and S. P. Azarova. 2021. "The Socio-Economic Importance of Education in a KnowledgeBased Economy." Studies in Systems, Decision and Control 316: 231-238.

Freitas, I. M. B., A. Geuna, and F. Rossi. 2013. "Finding the Right Partners: Institutional and Personal Modes of Governance of University-Industry Interactions." Research Policy 42 (1): 50-62.

Fuentes, D. C., and G. Dutrénit. 2012. "Best Channels of Academia-Industry Interaction for Long-Term Benefit." Research Policy 41: 1666-1682.

Fusso, N., F. P. Ducker, and M. Ito. 2013. “A Systems Thinking Review for Solving Short-Termism.” Management Research Review 36 (8): 805-822.

Gámez-Pérez, K. M., A. M. Sarmiento, H. Garcia-Reyes, and J. C. Velázquez-Martínez. 2020. “An International UniversityIndustry Collaboration Model to Develop Supply Chain Competences." Supply Chain Management 25 (4): $475-487$.

Guimón, J. 2013. "Promoting University-Industry Collaboration in Developing Countries." The Innovation Policy Plateform. doi:10.13140/RG.2.1.5176.8488.

Hair, J. F., M. Sarstedt, L. Hopkins, and V. G. Kuppelwieser. 2014. "Partial Least Squares Structural Equation Modeling (PLS-SEM): An Emerging Tool in Business Research.” European Business Review 26 (2): 106-121.

Hamidi, M. R., A. Babaee, A. Maleki, and M. Taghi Isaai. 2020. "Innovation Policy, Scientific Research and Economic Performance: The Case of Iran.” Development Policy Review 38 (3): 387-407.

Hanushek, E. A., and W. Ludger. 2007. "The Role of School Improvement in Economic Development." National Bureau of Economic Research Working Paper 12832.

Healey, M., A. Jenkins, and J. Lea. 2014. "Developing Research Based Curricula in Collage-Based Higher Education.” The Higher Education Academy 1-88.

Henseler, Jörg, and Wynne W. Chin. 2009. "A Comparison of Approaches for the Analysis of Interaction Effects Between Latent Variables Using Partial Least Squares Path Modeling.” Structural Equation Modeling 17 (1): 82-109.

Higueras-Rodríguez, L., M. Medina-García, and E. Molina-Ruiz. 2020. "Analysis of Courses and Teacher Training Programs on Playful Methodology in Andalusia (Spain).” Education Sciences 10 (4): 105. doi:10.3390/educsci10040105.

Hooshyar, D., M. Pedaste, K. Saks, Ä. Leijen, E. Bardone, and M. Wang. 2020. "Open Learner Models in Supporting SelfRegulated Learning in Higher Education: A Systematic Literature Review.” Computers and Education 154: 103878. doi:10.1016/j.compedu.2020.103878.

Iqbal, A. M. 2018. "Influence of National Innovation System on University-Industry Research Collaboration." Doctoral thesis, Universiti Teknologi Malaysia, Johor Bahru, Malaysia. http://eprints.utm.my/id/eprint/79054/.

Iqbal, A. M., A. S. Khan, S. Iqbal, and A. A. Senin. 2011. "Designing of Success Criteria-Based Evaluation Model for Assessing the Research Collaboration Between University and Industry." International Journal of Business Research and Management 2 (2): 59-73.

Iqbal, A. M., A. S. Khan, S. Iqbal, and A. A. Senin. 2013. "A Novel Cost Efficient Evaluation Model for Assessing ResearchBased Technology Transfer Between University and Industry." Sains Humanika 64 (2): 87-91.

Iqbal, A. M., A. S. Khan, and A. A. Senin. 2012. "Determination of High Impact Evaluation Metrics for Evaluating the University-Industry Technological Linkage.” International Journal of Physical and Social Sciences 2 (4): 111-122.

Iqbal, A. M., A. S. Khan, and A. A. Senin. 2015. "Reinforcing the National Innovation System of Malaysia Based on University-Industry Research Collaboration: A System Thinking Approach." International Journal of Management Sciences and Business Research 4 (1): 6-15.

Jones, S. E., and N. Coates. 2020. "A Micro-Level View on Knowledge Co-Creation Through University-Industry Collaboration in a Multi-National Corporation." Journal of Management Development 39 (5): 723-738.

Justman, M., and M. Teubal. 1995. "Technological Infrastructure Policy (TIP): Creating Capabilities and Building Markets." Research Policy 24 (2): 259-281.

Kadarova, J., L. Kalafusova, and M. Darkacova. 2014. "Holistic System Thinking as an Educational Tool Using key Indicators." Procedia - Social and Behavioural Science 143: 180-184.

Kafouros, M., C. Wang, P. Piperopoulos, and Z. M. Mingshen. 2015. "Academic Collaborations and Firm Innovation Performance in China: The Role of Region-Specific Institutions." Research Policy 44 (3): 803-817.

Khayyat, N. T., and J. D. Lee. 2015. "A Measure of Technological Capabilities for Developing Countries." Technological Forecasting \& Social Change 92: 210-223. 
Krejcie, R. V., and D. W. Morgan. 1970. "Determining Sample Size for Research Activities.” Educational and Psychological Measurement 30 (3): 607-610.

Kunc, M. 2008. “Using Systems Thinking to Enhance Strategy Maps.” Management Decision 46 (5): $761-778$.

Lai, I. K. W., and T. W. Lu. 2016. "How to Improve the University-Industry Collaboration in Taiwan's Animation Industry? Academic vs. Industrial Perspectives.” Technology Analysis and Strategic Management 28 (6): 717-732.

Lane, D. C., E. Munro, and E. Husemann. 2016. "Blending System Thinking Approaches for Organizational Analysis: Reviewing Child Protection in England.” European Journal of Operational Research 251 (2): 613-623.

Lee, D. Y., and S. Y. Lee. 2020. "A Study on the Effect of Regional Innovation System on Regional Competitiveness of Local Government: Focused on the Technological and Economic Effects." Test Engineering and Management 83: $4202-4211$.

$\mathrm{Li}, \mathrm{X}$. 2011. "Sources of External Technology, Absorptive Capacity, and Innovation Capability in Chinese State-Owned High-Tech Enterprises." World Development 39 (7): 1240-1248.

Lin, J. Y., and C. H. Yang. 2020. "Heterogeneity in Industry-University R\&D Collaboration and Firm Innovative Performance." Scientometrics 124 (1): 1-25. doi:10.1007/s11192-020-03436-2.

Liu, S. T. 2017. "A partial least squares structural equation modeling approach for examining multidimensional values of Taipei Zoo.” Asia Pacific Journal of Tourism Research 22 (8): 863-873. doi:10.1080/10941665.2017.1344716.

Maggioni, M. A. 2002. "The Development of High-Tech Clusters." In M. P. Feldman \& N. Massard (Eds.), Institutions and Systems in the Geography of Innovation (Economics of Science, Technology and Innovation, Vol. 25, pp. 309-339). Boston, MA: Springer. doi:10.1007/978-1-4615-0845-8_15.

Meek, V. L., U. Teichler, and M. L. Kearny. 2009. Higher Education, Research and Innovation: Changing Dynamics; Report on the UNESCO Forum on Higher Education, Research and Knowledge, 2001-2009. https://unesdoc.unesco.org/ark:/ 48223/pf0000183071.

Melamed-Varela, E., L. Navarro-Vargas, A. B. Blanco-Ariza, and E. Olivero-Vega. 2019. "University-Industry-Government Linkage to Promote Innovation at Regional Systems: Documentary Research.” Revista de Estudios Regionales 114: 147-169.

Messeni Petruzzelli, A., and G. Murgia. 2020. "University-Industry Collaborations and International Knowledge Spillovers: A Joint-Patent Investigation.” Journal of Technology Transfer 45 (4): 958-983.

Park, Y. S., L. Konge, and A. R. Artino. 2020. "The Positivism Paradigm of Research.” Academic Medicine 95 (5): $690-694$.

Parmentola, A., M. Ferretti, and E. Panetti. 2020. "Exploring the University-Industry Cooperation in a low Innovative Region. What Differences Between Low Tech and High Tech Industries?" International Entrepreneurship and Management Journal. doi:10.1007/s11365-020-00671-0.

Phillips, D. C., and N. C. Burbules. 2000. Postpositivism and Educational Research. New York: Rowman \& Littlefield.

Pontarollo, N., M. Orellana, and J. Segovia. 2020. "The Determinants of Subjective Well-Being in a Developing Country: The Ecuadorian Case." Journal of Happiness Studies 21 (8): 3007-3035.

Razorenov, Y. I., and K. V. Vodenko. 2020. "Innovative Development of the National University System in Russia: Trends and key Elements." International Journal of Sociology and Social Policy. doi:10.1108/IJSSP-03-2020-0073.

Richmond, B. 1994. "System Thinkers and System Thinking." System Dynamics Review 10 (2-3): 95-99.

Sarriot, E., M. Morrow, A. Langston, J. Weiss, J. Landegger, and L. Tsuma. 2015. "A Causal Loop Analysis of the Sustainability of Integrated Community Case Management in Rwanda." Social Science and Medicine 131: 147-155.

Sedlacko, M., A. Martinuzzi, and K. Dobernig. 2014. "A Systems Thinking View on Cloud Computing and Energy Consumption." Proceedings of ICT for Sustainability, ICT4S 2014, Stockholm. doi:10.2991/ict4s-14.2014.11.

Senge, P. M. 2006. The Fifth Discipline, The Art and Practice of the Learning Organization. 1st ed. London: Doubleday.

Subramanian, G. H., and K. Wang. 2019. "Systems Dynamics-Based Modeling of Data Warehouse Quality." Journal of Computer Information Systems 59 (4): 384-391.

Tenenhaus, M., and V. Esposito Vinzi. 2005. "PLS Regression, PLS Path Modeling and Generalized Procrustean Analysis: A Combined Approach for Multiblock Analysis." Journal of Chemometrics 19: 145-153.

Ting, S. H., S. Yahya, and C. L. Tan. 2020. "Importance-Performance Matrix Analysis of the Researcher's Competence in the Formation of University-Industry Collaboration Using Smart PLS.” Public Organization Review 20 (2): $249-275$.

Tseng, F. C., M. H. Huang, and D. Z. Chen. 2020. "Factors of University-Industry Collaboration Affecting University Innovation Performance." Journal of Technology Transfer 45 (2): 560-577.

Veis, Y. V., O. Y. Eremicheva, I. B. Kostyleva, and V. S. Tikhonov. 2021. "HR Training in Digital Economy: Innovative Investment Projects." Lecture Notes in Networks and Systems 139: 688-696.

Wang, S., and R. A. Noe. 2010. "Knowledge Sharing: A Review and Directions for Future Research." Human Resource Management Review 20: 115-131.

White, D. 1995. “Application of Systems Thinking to Risk Management." Management Decision 33 (10): 35-45.

Wilson, L. E., M. E. Gahan, C. Lennard, and J. Robertson. 2020. "Why Do We Need a Systems Thinking Approach to Military Forensic Science in the Contemporary World?" Australian Journal of Forensic Sciences 52 (3): 323-336.

Wu, Y., F. Gu, Y. Ji, J. Guo, and Y. Fan. 2020. "Technological Capability, Eco-Innovation Performance, and Cooperative R\&D Strategy in New Energy Vehicle Industry: Evidence from Listed Companies in China." Journal of Cleaner Production 261: 121157. doi:10.1016/j.jclepro.2020.121157.

Xu, D. 2013. "Research on Improving the Technological Innovation Capability of SMEs by University-Industry Collaboration." Journal of Engineering Science and Technology Review 6 (2): 100-104. 